\title{
The ups and downs of cellular stress: the "MAM hypothesis" for Bipolar disorder pathophysiology
}

\author{
Ana Catarina Pereira' ${ }^{1}$ Rosa Resende ${ }^{1}$, Sofia Morais ${ }^{2,3}$, Nuno Madeira ${ }^{2,3}$, and Claudia Fragão Pereira ${ }^{1,3}$
}

Special Issue on the Neurobiology of Mental IIIness

\begin{abstract}
Mental health problems constitute the largest single source of world economic burden, with an estimated global cost greater than cardiovascular disease, cancer or diabetes individually. In the European Union mental disorders affect millions of people and these numbers are expected to rise as result of Europe's ageing population. Given the biological causes of many of these disorders, most studies focus on their molecular basis. Bipolar disorder (BD) is characterized by mood swings between depression and mania resulting in cognitive and functional impairments that require lifetime treatment. Recurrent mood episodes, residual symptoms, functional impairment, psychosocial disability with high rates of divorce, unemployment, drug abuse and suicide attempting, and significant medical comorbidities such as metabolic and cardiovascular diseases cannot be efficiently controlled even with proper use of current treatments. Moreover, delayed diagnosis/misdiagnosis is frequent because reliable biomarkers are absent. Therefore, a better understanding of $\mathrm{BD}$ pathophysiology is a prerequisite for the design of new drugs and their implementation in clinical practice as well as to develop biomarkers for a more accurate and earlier diagnosis and/or evaluation of therapeutic response. This review summarises the association between decreased cellular resilience towards stress and BD. Since the key stress-response mediator Mitochondria-Associated Membranes (MAMs) modulate several BD relevant processes such as mitochondrial dysfunction and oxidative stress, $\mathrm{Ca}^{2+}$ deregulation and cytoskeleton abnormalities, endoplasmic reticulum stress responses, loss of proteostasis and inflammasome activation, we propose the "MAM hypothesis" for BD pathophysiology. Targeting MAM-associated signaling pathways can be a promising investigation avenue to identify novel therapeutic strategies.
\end{abstract}

Keywords: Bipolar disorder, Endoplasmic reticulum, Mitochondria, Mitochondria-associated membranes, Cellular resilience, Cellular stress, Plasticity.

\footnotetext{
'Center for Neuroscience and Cell Biology, University of Coimbra, Portugal 2Psychiatry Department, Coimbra Hospital University Centre, Portugal ${ }^{3}$ Faculty of Medicine, University of Coimbra, Portugal
}

Correspondence: Cláudia Maria Fragão Pereira Center for Neuroscience and Cell Biology

University of Coimbra, 3004-517 Coimbra, Portugal

Email: claudia.mf.pereira@gmail.com
Citation: Prereira et al. The ups and downs of cellular stress: the "MAM hypothesis" for Bipolar disorder pathophysiology. International Journal of Clinical Neurosciences and Mental Health 2017; 4(Suppl. 3):S04

DOI: https://doi.org/10.21035/ijcnmh.2017.4(Suppl.3).S04 


\section{Bipolar Disorder}

$\mathrm{BD}$ is a chronic psychiatric illness with a remitting course, affecting $2.4 \%$ of the general population [1], characterized by mood swings between manic and depressive states that result in cognitive and functional impairments, high health care costs and premature mortality $[2,3]$.

$\mathrm{BD}$ is the sixth leading cause of disability worldwide responsible for loss of more disability-adjusted life-years than all forms of cancer and major neurological conditions [4]. BD is associated with greatly impaired quality of life and increased physical health burden [5]. Moreover, BD patients tend to have high rates of divorce, unemployment, drug abuse and crime as consequence of impaired social cognition, and its impact on patients can be devastating, with approximately $23 \%$ of patients with BD reported having suicide attempts [6]. Moreover, individuals with BD diagnosis have a high risk of medical comorbidities such as metabolic (diabetes, obesity and metabolic syndrome) and cardiovascular disorders [7].

Current knowledge of BD's neurobiology and pathophysiology is still modest [8] and with no clear biological markers available, early diagnosis is presently a great challenge to clinicians.

Pharmacological therapy is often the first-line treatment for BD, followed by psychological [9] and psychosocial interventions [10]. For maintenance pharmacological treatment the main goal is to prevent recurrences of mood episodes, using mood stabilizers (e.g. lithium, valproate, lamotrigine and carbamazepine) and atypical antipsychotics (e.g. olanzapine, aripiprazole, quetiapine and risperidone) or conventional antidepressants for depressive phases (e.g. selective serotonin reuptake inhibitors or bupropion) [11]. Psychosocial treatments include individual psychotherapies, supportive group therapies, education about the disease and focus on treatment adherence and self-care [12]. Furthermore, polypharmacy is still common in BD treatment, reflecting the gap between research and clinical practice. Currently available drugs are primarily targeted at relieving symptoms, are often only partially effective and have significant side effects. Thus, a better understanding of the underlying pathophysiological mechanisms to identify potential therapeutic targets is a prerequisite for the design of new drugs as well as to develop biomarkers that help in a more accurate and earlier diagnosis and/or to evaluate therapeutics response.

\section{Impaired cellular resilience}

A growing body of evidence suggests that mood disorders are associated with regional atrophic brain changes that may be closely associated with abnormalities in cellular plasticity, including the resilience of brain cells to resist or adapt to environmental stressors [13]. Structural neuroimaging and postmortem studies have highlighted anatomical and neuropathological alterations in BD patients such as ventricular enlargement, decreased levels of neuronal integrity markers and reduction of neuronal density in specific brain areas, suggesting abnormalities in the cellular resilience towards stressful conditions of neurons and glia cells [14]. These alterations can explain several clinical features such as the progressive shortening of inter-episode interval with each recurrence occurring in consort with reduced probability of treatment response as the illness progresses. This hypothesis is supported by recent genetic studies in postmortem prefrontal cortex samples, which identified the EGR3 regulatory unit (regulon) that translates environmental stimuli into long-term changes in the brain to be robustly repressed in BD patients [15], further suggesting that an impaired response to stress influences BD risk.

Cellular modeling in BD using lymphoblastoid cell lines, fibroblasts, olfactory neuronal epithelium and neurons reprogrammed from induced pluripotent stem cells (iPSCs) [16-18], has proven useful to understand its biological basis, and potential pathways have been identified, especially in cellular resilience-related mechanisms. The most replicated findings that show consistency with genome-wide association studies (GWAS), brain-imaging and post-mortem brain expression include abnormalities in endoplasmic reticulum (ER)-related stress responses, mitochondrial function and $\mathrm{Ca}^{2+}$ signaling, which are often reversed in vitro with lithium. Furthermore, patient-derived cellular models also support that alterations in microRNAs (miRNAs), glia and immune cell signaling, cytoskeleton as well as oxidative stress, inflammasome activation, autophagy and apoptosis play a relevant role in BD pathophysiology [8,19-29].

\section{ER-mitochondria miscommunication}

The above BD-related events are associated with functions localized to a subdomain of the ER, known as mitochondria-associated membranes (MAMs), which are lipid raft-like domains closely opposed to mitochondria in such a way that the two organelles can physically and biochemically communicate with each other. ER-mitochondria juxtaposition is crucial for efficient inter-organelle $\mathrm{Ca}^{2+}$ transmission controlling mitochondrial bioenergetics and pro-survival/pro-death pathways and determining cell fate under stressful conditions [30, 31]. The last few years have been marked by increased research on the molecular structure and function of MAMs, which provided a greater knowledge of the structural proteins dynamically associated with the ER-mitochondria contacts under physiological and non-physiological conditions. MAMs functions elucidation allowed to understand that MAMs role is much more important than it would be anticipated. MAMs are responsible for regulating mitochondrial shape and motility, as well as bioenergetics and redox status. Besides that, MAMs have a central role in the modulation of several key processes for cell survival, such as ER stress, autophagy, 
inflammasome signaling and apoptosis [32]. MAMs composition and abundance are highly dynamic being modulated by metabolic demands and cellular insults in order to adapt to different conditions. Under acute or chronic ER stress normal ER-mitochondria cross-talk is affected and this circumstance may cause several dysfunctions, such as metabolic impairment, changes in redox balance and cell death control, which, in turn, may be the source of various central nervous system (CNS) disorders where ER stress plays a central role $[33,34]$ and as a consequence of that develop morphological and biochemical alterations in MAMs [35]. Therefore, changes of the ER-mitochondria axis could be responsible for the onset and progression of several diseases, including cancer, diabetes, obesity and neurodegenerative disorders [33]. Sigma-1 receptor (Sig$1 \mathrm{R})$, an intracellular chaperone that resides specifically at the ER-mitochondria interface, modulates inter-organelle $\mathrm{Ca}^{2+}$ signaling [36]. Beyond these functions, MAM-resident Sig-1R is also important to trigger and to fit anti-stress responses. Under stress conditions, this receptor promotes passage of stress signals from the ER to the nucleus through its interaction with various receptors such as the N-methyl-D-aspartate receptors (NMDARs), ion channels, kinases and numerous regulatory key proteins residing on ER, MAM, nucleus or in the cytosol. Based on these complex intracellular actions the Sig-1R has been conceptualized as a pluripotent modulator in living systems with pleiotropic protective effects. Recent studies found that the Sig- $1 \mathrm{R}$ regulates bioenergetics, free radical generation, oxidative stress, unfolded protein response (UPR) and cytokine signaling, as well as morphogenesis of neuronal cells, such as neurite outgrowth, synaptogenesis, and myelination, which can be disturbed by cellular stress [37]. Their activation may therefore control a variety of stress-related cellular systems, thus contributing to a cellular defense system that protects the nervous system against chronic stress. In the last two decades, a considerable amount of clinical data demonstrated the role of Sig$1 \mathrm{R}$ in various pathologies. In particular ample evidence including the presence of genetic variants within SIGMA1R and the interaction of numerous antidepressants with these receptors, suggested a role of Sig- $1 \mathrm{R}$ in affective disorders [38,39]. Accordingly, a genetic polymorphism is a risk factor for schizophrenia and Sig-1Rs levels are significantly reduced in the brain of schizophrenic patients [40]. Currently, some drugs (e.g., fluvoxamine, fluoxetine, escitalopram, donepezil, ifenprodil), which have been used in humans, and some endogenous neurosteroids (e.g. dehydroepiandosterone) have high to moderate affinity to Sig-1R and exert antidepressant-like and neuroprotective actions supporting their clinical implication in numerous neuropsychiatric diseases [38]. The significant advances in Sig-1R research can be translated into future pharmacological approaches able to control the cellular stress systems based on a better understanding of upstream and downstream intracellular signaling cascades [41].
The above evidences support the "MAM hypothesis" for BD pathophysiology (Figure 1), which considers that ER-mitochondria miscommunication at MAMs is an initial event leading to diminished cellular resilience to stressful conditions and that approaches targeting these specific inter-organelle structures can lead to new treatment strategies and early diagnosis biomarkers. This novel hypothesis is supported by studies demonstrating modifications of several MAM-modulated cellular processes in BD patients, namely $\mathrm{Ca}^{2+}$ dyshomeostasis and cytoskeleton abnormalities, changes in the ER stress responses, mitochondrial dysfunction and oxidative stress, proteostasis (autophagy) impairment and inflammasome activation.

\section{$\mathrm{Ca}^{2+}$ dyshomeostasis and cytoskeleton abnormalities}

Over the last few years, several studies have identified common single polymorphisms (SNPs) in calcium voltage-gated channel subunit alpha 1C (CACNA1C) and ankyrin-3 (ANK3) in BD patients, implicating these as susceptibility genes for BD $[42,43]$. These findings support that $\mathrm{Ca}^{2+}$ deregulation is involved in $\mathrm{BD}$ pathophysiology, as both CACNA1C and ANK3 encode $\mathrm{Ca}^{2+}$ signaling-related proteins: Cav1.2 $\mathrm{Ca}^{2+}$ channel are important regulators of $\mathrm{Ca}^{2+}$ influx into cells stimulated by $\mathrm{ER} \mathrm{Ca}^{2+}$ depletion and are critical for normal brain development and plasticity $[44,45]$ and ankyrin directly interacts with the ER 1,4,5-inositol triphosphate receptor (IP3R), which is localized at MAMs and is responsible for ER $\mathrm{Ca}^{2+}$ release [46]. Carriers of the CACNA1C risk polymorphism rs1006737 exhibit greater age-related thickness of cortical brain areas widely associated with mood regulation in $\mathrm{BD}$ [47]. Furthermore, recent studies demonstrate that the genetic variation rs10761482 of the ANK3 gene affects age-related brain atrophy [48]. Bioinformatics analysis of differentially expressed proteins identified by proteomics in postsynaptic density from the anterior cingulate cortex of $\mathrm{BD}$ patients further implicated changes in $\mathrm{Ca}^{2+}$ signaling in $\mathrm{BD}$ pathophysiology [49]. Accordingly, L-type $\mathrm{Ca}^{2+}$ channel (LTCC) antagonists have been used in BD for over 30 years without becoming an established therapeutic approach, however, additional genetic, molecular and pharmacological data are required to improve the selectivity, efficacy and tolerability of LTCC antagonists [50].

Neurons derived from individuals with mutations and deficiencies in odd Oz/ten-m homolog 4, TENM4 (ODZ4) genes show abnormal characteristics [51]. ODZ4, a human homolog of the Drosophila pair-rule gene ten-m (odz), encodes teneurin, a transmembrane protein that organizes the cytoskeleton [52], a crucial event for ER-mitochondria contact and $\mathrm{Ca}^{2+}$ transfer [53]. Recently, by profiling the proteomics of BD-hiPSC-derived neurons, data obtained by Tobe and colleagues implicate aberrant posttranslational modification of collapsin response mediator protein-2 (CRMP2), a cytoskeleton-binding protein that is pres- 


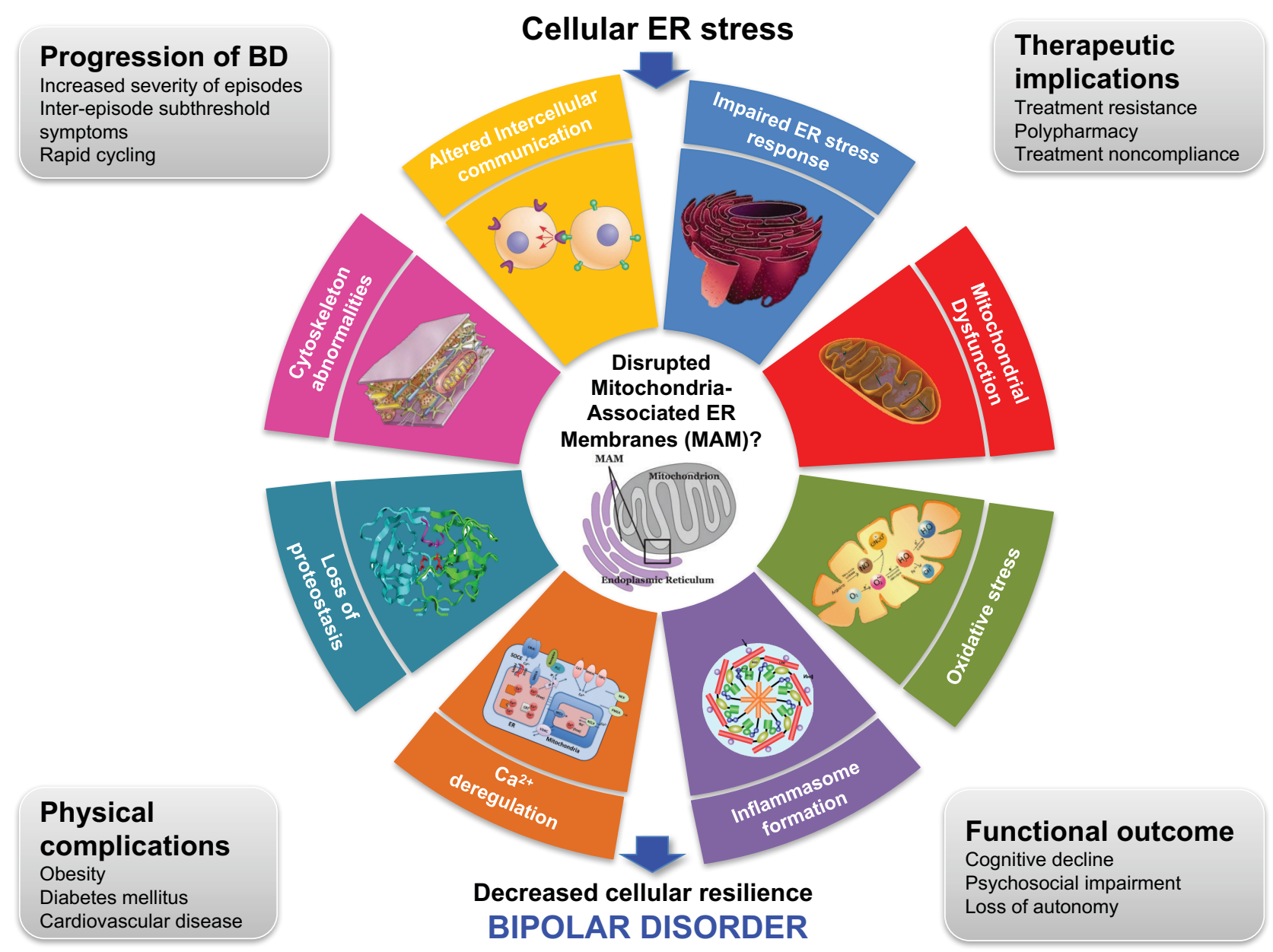

Figure 1. The "Mitochondria-Associated ER Membrane (MAM) Hypothesis" for BD pathophysiology. Patient's cells are chronically exposed to stressful conditions leading to MAMs disruption and subsequent perturbation of cells' ability to cope with stress (cellular resilience), which arises from loss of proteostasis, changes in lipid and calcium homeostasis, dysregulation of intercellular communication, impairment of ER stress responses, mitochondrial dysfunction and oxidative stress, formation of inflammasome and induction of apoptosis, which all have been described in BD. Impairment of these MAM-regulated events decreasing cellular resilience can explain several BD outcomes namely its progressive nature, the functional outcome, the physical complications and also the therapeutic implications, supporting MAMs as promising therapeutic targets for BD.

ent particularly in dendritic spines, in abnormal Ca flux [27]. Evidence from clinical studies and animal models supports that disturbed microtubule cytoskeleton underlie abnormalities in neuronal cell architecture, namely in dendritic complexity and synaptic density changes, which disrupt synaptic connectivity, in the brains of subjects with mood disorders such as BD [54]. Aberrant microtubular organization in patients with $\mathrm{BD}$ might arise from diminished microtubule-associated proteins expression, which in turn may affect $\mathrm{Ca}^{2+}$ voltage-activated currents [55]. Genome-wide association data from the Psychiatric Genomics Consortium suggests that deregulation of cytoskeleton remodeling, in particular of actin cytoskeleton, which has direct impacts on endocytosis, phagocytosis, exocytosis, vesicle trafficking, neuronal maturation and migration, neurite outgrowth and synaptic density and plasticity, is implicated in $\mathrm{BD}$ [56]. A recent study shows that the genetic deletion in mice of neural abelson-related gene-binding protein 2 (nArgBP2), which interacts with the postsynaptic scaffolding proteins SAP90/PSD95-associated protein 3 (SAPAP3) and $\mathrm{SH} 3$ and multiple ankyrin repeat domains 3 (Shank3 ) that are implicated in the pathogenesis of various mood dis- orders, including BD, leads to manic/bipolar-like behavior resembling symptoms of BD by controlling actin dynamics that causes a robust and selective inhibition of excitatory synapse formation [57].

\section{Compromised ER stress response}

The ER consists of a large membranous network and is the cellular site for synthesis, folding, and maturation of most secreted and transmembrane proteins. It has many different functions including the translocation of proteins across the ER membrane, the integration of proteins into the membrane, the folding and modification of proteins in the ER lumen, the synthesis of phospholipids and steroids on the cytosolic side of the ER membrane, and the storage of $\mathrm{Ca}^{2+}$ ions in the ER lumen and their regulated release into the cytosol $[19,33]$. Lately, ER has been put forward as a key organelle in inducing chronic stress associated with many brain disorders including neuropsychiatric diseases such as BD [58].

ER stress is caused by the accumulation of unfolded and misfolded proteins in the ER lumen leading to disturbed 
ER homeostasis. ER stress activates a signaling cascade called the UPR, which triggers a set of transcriptional and translational events that restore ER homeostasis, promoting cell survival and adaptation $[59,60]$. If this adaptive response fails, a terminal UPR program commits such cells to apoptosis [61]. The outcomes of the cellular response are influenced by ER stress levels [62]. When ER stress is mild, the cell can recover and adapt. However, when ER stress is prolonged or too severe, these mechanisms fail to restore proteostasis leading to autophagy and apoptosis if the stress cannot be alleviated. Canonical mammalian pathways of the UPR pathway involve three specialized ER stress-sensing proteins: protein kinase R-like endoplasmic reticulum kinase (PERK), inositol-requiring enzyme $1 \alpha$ (IRE1 $\alpha$ ) and activation of transcription factor 6 (ATF6) [63]. In cells undergoing ER stress, the ER chaperone, glucose-regulated protein 78 (GRP78) dissociates from the ER transmembrane sensors [64] and promotes their activation, thus inducing phosphorylation and oligomerization of IRE1 $\alpha$ and PERK, as well as the translocation of ATF6 to the Golgi where it is cleaved by Site 1 and Site 2 proteases (S1P and S2P) [63]. Active IRE1 $\alpha$ processes mRNA encoding for X-box binding protein 1 (XBP1), a transcription factor that up-regulates genes that encode mediators of the ER-associated degradation (ERAD) pathway, organelle biogenesis and protein quality control [65]. PERK activation reduces protein load in the ER by decreasing general protein synthesis through phosphorylation of the $\alpha$-subunit of eukaryotic translation-initiation factor $2 \alpha(\mathrm{eIF} 2 \alpha)$, which paradoxically increases selective translation of activating transcription factor 4 (ATF4) mRNA [66]. ATF4 is a member of the bZIP family of transcription factors that activates expression of several UPR target genes involved in antioxidant responses, such as the transcription factor Nrf2, apoptosis and autophagy $[67,68]$. In cells experiencing ER stress, ATF6 is cleaved at the Golgi apparatus allowing the newly released cytosolic domain to translocate to the nucleus where it regulates ER chaperones, ERAD-related genes, and proteins involved in organelle biogenesis [69]. Severe and/or chronic ER stress can have, however, negative effects leading to apoptosis through different pathways such as: the rise of reactive oxygen species (ROS) and $\mathrm{Ca}^{2+}$ levels, activation of the ER-resident caspase-12 (in rodents or caspase-4 in humans), CAAT/enhancer binding protein homologous protein (CHOP) or c-Jun NH2-terminal kinase (JNK) [70]. Several evidences highlight the role of ER-related stress response in BD. For instance, the fact that the expression of the BiP protein (GRP78 protein / glucose-regulated protein, $78 \mathrm{kDa}$ ), a chaperone that is highly expressed in the ER, can be up-regulated by different types of mood stabilizers, allowed to hypothesize that the ER, an organelle that has been described to be implicated in the cellular response to different forms of cellular stress, may be involved in the pathophysiology of BD. Lately, evidence emerged revealing that lithium and valproic acid (VPA), drugs widely used in the treatment of $\mathrm{BD}$, increase the expression of ER chaperones and activate the unfolded protein response element (UPRE), suggesting that their mode of action includes UPR activation [71]. Furthermore, genetic association studies have given an important contribution in order to strengthen this hypothesis by demonstrating significant association of GRP78 promotor polymorphisms with BD and linkage between other ERstress associated genes like XBP1 (X-box binding protein 1) or GRP94 (glucose-regulated protein, $94 \mathrm{kDa}$, synonym for heat shock protein HSP90B1) and BD pathology [21]. $\mathrm{XBP} 1$, a pivotal gene in the ER stress response, has been considered a genetic risk factor for BD and a polymorphism in its promoter was found less effective to reduce ER stress in BD patients-derived cells [72]. Also, changes in the levels of several ER UPR-related proteins have been described in BD. In healthy controls but not in BD patients it was found an increase in the levels of GRP78, eIF2 $\alpha-P$, and CHOP after ER stress induction, which represents a cellular response to inhibit global protein synthesis and, therefore, functions as a defense mechanism triggered to cope with stress and restore ER homeostasis [19]. Tunicamycin-induced cell death was found significantly higher in patients compared to controls and, more importantly, early-stage patients did not differ from controls while the late-stage patients showed an impaired ER stress response [19]. These findings are in accordance with the "MAM hypothesis" for BD pathophysiology (Figure 1), which hypothesizes that ER-mitochondria miscommunication at MAMs is an initial event diminishing cellular resilience to stressful conditions in BD patients. Patients presenting Darier's disease with a mutation in the ER $\mathrm{Ca}^{2+}$ pump SER$\mathrm{CA}$ have high rates of comorbid $\mathrm{BD}$ and/or the presence of manic-like symptoms [73] further supporting deregulated ER stress responses in BD. Moreover, a Bcl-2 polymorphism was shown to contribute to $\mathrm{Ca}^{2+}$ dyshomeostasis in $\mathrm{BD}$ through direct regulation of ER IP3R and Bcl-2 knockout mice have increased anxiety-like behaviours [74]. Accordingly, deregulation of $\mathrm{Ca}^{2+}$ signaling is one of the most reproducible observations in $\mathrm{BD}$ and is supported by the alteration of transcripts involved in $\mathrm{Ca}^{2+}$ signaling in iPSCs from BD patients [22]. Finally, Disrupted-In-Schizophrenia 1 (DISC1), a genetic candidate for $\mathrm{BD}$, also modulates transcriptional responses to ER stress [75].

\section{Mitochondrial dysfunction}

Mitochondria are small organelles that play a central role in cell metabolism because they are the main energy providers by converting metabolites to adenosine-5-triphosphate (ATP). Based on the chemiosmotic theory, most of the ATP produced by ATP synthase arises from the electrochemical gradient generated by the electron transport chain across the inner membranes of mitochondria [76]. Furthermore, mitochondria are also key organelles in diverse pathophysiological contexts, such as the regulation 
of free radicals production, $\mathrm{Ca}^{2+}$ homeostasis and redox signaling, and also take part in the intrinsic pathway of apoptosis [76,77]. Besides that, mitochondria are involved in modulation of neuronal activity, neuroplasticity and morphogenesis because their distribution and activity are key factors for the normal neuronal development and synaptic plasticity. For instance, they control the neurotransmitter's exocytosis and ion homeostasis in presynaptic nerve terminals $[76,78]$.

There is increasing evidence showing that mitochondrial dysfunction is implicated in different diseases, such as cardiovascular diseases, neuromuscular neuropathies and neurodegenerative and neuropsychiatric disorders [76]. Impaired mitochondria function can arise from mutations or polymorphisms of mitochondrial DNA (mtD$\mathrm{NA}$ ), deregulation of free radicals production leading to oxidative stress, impaired phospholipid metabolism and glycolytic shift, ATP synthesis decrement and changes in $\mathrm{Ca}^{2+}$ homeostasis, which were already implicated in mood disorders [76,77]. Kato and Kato were the first to propose the mitochondrial dysfunction hypothesis for BD based on the presence of mtDNA abnormalities and amino acid substitutions in specific candidate genes in BD patients, such as the mtDNA polymorphisms 5178C and 10398A; they found that these abnormalities were associated with decreased brain intracellular $\mathrm{pH}$ and alteration of intracellular $\mathrm{Ca}^{2+}$ signaling, respectively [79]. Numerous evidences that emerged recently support that impaired mitochondrial function is associated with mood disorders and in particular with BD [76,77,80,81].

Multiple lines of evidence suggest that mood abnormalities arising from alterations of mitochondria and energy production are a key feature in the pathophysiology of BD [82]. Evidence of mitochondrial dysfunction in BD includes decreased levels and activity of nuclear-encoded subunits of mitochondrial respiratory complexes, decreased $\mathrm{pH}$ and altered oxidative phosphorylation in the brains of $\mathrm{BD}$ patients [83]. Elevated lactate levels in $\mathrm{BD}$ patient's brain suggest a shift from aerobic to anaerobic metabolism, further supporting mitochondrial dysfunction in $\mathrm{BD}$ [82]. Changes in the expression of mitochondria-related genes also corroborate the mitochondrial impairment in BD. Maeda and colleagues [84] showed a decrease in DISC1 expression in lymphoblasts with the DISC1 risk haplotype for $\mathrm{BD}$, when compared to lymphoblasts from control subjects. Scola and colleagues demonstrated that patients with $\mathrm{BD}$ have a differential gene expression that increases the sensitive towards dysfunction of the electron transfer process [85]. The NDUFV2 gene, which is required for the first step in the electron transfer process, NDUFS8, which controls the electron relay, and NDUFS7, which is responsible for the reduction of ubiquinone to ubiquinol, are down-regulated in BD patients. Later on, an up-regulation of NDUFV2 was detected in depressed state when compared with euthymic state [86]. Yoshimi and colleagues obtained additional evidences corroborating the theory of mitochondrial dysfunction in BD. Through metabolomic assays of cerebrospinal fluid (CSF) obtained from $\mathrm{BD}$ patients, they observed that deregulation of isocitrate metabolism in the mitochondrial citric acid cycle is relevant in the pathogenesis of BD [87]. Moreover, mitochondrial dysfunction has been identified as the cause of the neuroprogression and cognitive impairment observed in $\mathrm{BD}$. As mentioned above, brain mitochondria are essential for neurotransmission and neuronal plasticity, including long-term potentiation induction, which is required for cellular resilience under stress conditions and behavioral adaptation. Therefore, mitochondrial dysfunction will consequently lead to cellular resilience alterations, which play a major role in BD [77]. Mood stabilizers are used to treat BD because they have modest antidepressant properties and avoid the recurrence of new mood episodes [88]. Recently, several studies clarified the mechanisms of action of these stabilizers, revealing that they affect mitochondrial function [77].

Taken together, the above evidence allowed to face mitochondrial dysfunction as the most robust alteration found in the postmortem BD brain [77].

According to the MAM hypothesis, communication between ER and mitochondria at MAMs level is required to regulate cell homeostasis and allow maintenance of cellular resilience under stress conditions. Thus, if both mitochondrial integrity and function are impaired this communication will be affected, and the downstream events will be compromised.

\section{Oxidative stress}

A cell is in an oxidative stress state when an imbalance between the production of ROS and antioxidant activities occurs [89]. Mitochondria, in addition to be the major energy source of the cells, are also considered the main origin of ROS since superoxide radical is generated as a consequence of the electron transport chain, which may give rise to oxidative stress and subsequent cell damage. As result of accumulation of oxidative lesions, several physiological functions can be affected, increasing disease's incidence concomitantly with a reduction in life span [90]. Despite the physiologic relevance of low and intermediary ROS levels that preserve cell survival [91] oxidative stress has been faced as a potential unifying mechanism contributing to several human pathologies since high ROS concentrations, above the clearance capacity of the cell cause oxidative stress, mitochondrial dysfunction, cellular damage, and, in numerous cases, cell death [92]. Accordingly, increasing evidence suggests the involvement of oxidative stress in the pathology and progression of $\mathrm{BD}$ and several studies report the increase in the levels of oxidative stress markers in BD patients $[26,77]$. Lipid peroxidation and nitric oxide levels were shown significantly increased in red blood cells or serum from BD patients compared to healthy controls $[93,94]$ and increased protein oxidation and ni- 
tration was detected in synaptosomes and mitochondria isolated from patients' postmortem prefrontal cortex [95]. 4-hydroxy-2-nonenal (HNE), which is considered a strong marker of oxidative stress that leads to the formation of HNE-protein adducts able to alter cellular homeostasis and cause the development of a pathological state, was found in the cortex of bipolar patients [96]. Oxidative damage of nucleic acids was also observed and was found to be increased in peripheral and post-mortem patient brain samples $[93,94,97,98]$. However, contradictory data on the activities of antioxidant enzymes such as superoxide dismutase, catalase and glutathione peroxidase was reported in BD patients [94]. Recent evidences support that the cellular effects of oxidative stress worsen with time and number of manic episodes. Despite unchanged levels of the main cerebral antioxidant glutathione were found in the anterior cingulate cortex of BD patients in comparison with healthy controls [99], Rosa and collaborators, using blood samples from patients with different ages of disease onset, showed that glutathione levels are lower in $\mathrm{BD}$ patients and observed a negative correlation with the age at onset [100]. In addition, higher protein carbonyl and lipid hydroperoxide content were determined in adults compared to adolescents with BD [101] and the increased levels of an early component of the peroxidation chain in euthymic older patients with BD support the hypothesis of a persistent effect of ROS in patients with $\mathrm{BD}$ into late life [102]. It was observed in a recent exploratory study that the plasma levels of oxidative stress markers were lower in adolescents with fully syndromal BD than controls, while levels in the at-risk groups were between healthy controls and fully syndromal BD supporting a role of oxidative stress in BD risk progression [103]. Furthermore, Andreazza and colleagues observed that superoxide dismutase activity was higher in manic and depressed patients compared to euthymic patients and controls [104]. Of relevance, the antioxidant properties of numerous mood stabilizers were described [105-110].

\section{Proteostasis (autophagy) impairment}

Protein misfolding and aggregation have been described as relevant events in many neurodegenerative and neuropsychiatric diseases [111]. The majority of neuropsychiatric diseases, such as schizophrenia, BD, depression and autism are associated with variations in the DISC1 gene that is expressed in neuronal dendritic spines controlling spine and synapse development. These variations seem to promote DISC aggregation since dimers, octamers, higher oligomers and insoluble aggregates of DISC1 have been identified in some of these chronic illnesses. The formation of DISC1 aggregates was recently associated with a decrease in free soluble protein and a gain of toxic function leading to the impairment of mitochondrial axonal transport [111]. Thus, the occurrence of certain mutations can trigger the accumulation of misfolded proteins, which might lead to the formation of protein aggregates [34,111] that can affect several mechanisms, such as mitochondrial function, slowing axonal transport and promoting oxidative stress [111].

Proteostasis, which means regulated protein homeostasis, is a complex process that requires the dynamic coordination between efficient folding of newly synthesized proteins, quality control and degradation mechanisms to reduce the load of unfolded and/or misfolded proteins to prevent abnormal protein aggregation [34]. Chaperones are central players in proteostasis maintenance since they are responsible for protein folding in cells, acting as an effective first line defense against protein misfolding through the recognition of non-native conformations of polypeptides that are sent for refolding. When this protective mechanism, which allows recovering the native conformation of proteins, fails degradation pathways - ubiquitin proteasome pathway (UPS) and autophagy-are activated. UPS and lysosomal autophagic degradation pathways are complementary in their mode of action, acting as a second barrier to restore proteostasis. When the proteasome is defective or saturated, or if there is an excess of ROS, the accumulation of misfolded proteins occurs leading to the formation of both toxic soluble oligomers and larger aggregates that can then be eliminated by autophagy [34,111]. However, in several neurodegenerative disorders such as Parkinson's disease and amyotrophic lateral sclerosis, autophagic vacuoles (autophagosomes or autophagolysosomes) accumulate suggesting lysosomal dysfunction. Due to the impairment of the autophagic pathway, misfolded protein and aggregates are not cleared from the cells resulting in cell death [111].

Lithium, a classic mood stabilizer, was also proposed for treatment of Huntington's disease (HD) and ALS because it was shown to be able to induce autophagy. In combination with two other mood-stabilizing and anticonvulsant drugs, VPA and carbamazepine (CBZ), lithium was suggested to induce autophagy through inhibition of inositol monophosphatase (IMPase), an enzyme that catalyzes the hydrolysis of inositol monophosphate into free inositol $[111,112]$. The fact that lithium is a drug widely used in the treatment of $\mathrm{BD}$, together with the evidence showing that patients with neurodegenerative disorders where it has already been demonstrated the impairment in autophagy - exhibit several neuropsychiatric comorbidities like depression and apathy, anticipate autophagy deregulation in BD. According to this evidence, an increment in autophagy could be beneficial in BD treatment. However, it is important to take into account that these are indirect evidences, indicating that further studies are required.

\section{Inflammasome activation}

The majority of diseases, namely brain diseases, have been associated with an important inflammatory component [113]. Inflammation is a protective immune response triggered by the immune system in response to harmful stimu- 
li, such as pathogens, dead cells or irritants. Immune activation within the CNS occurs to aid repair and regeneration of tissues, hence preventing cell death. However, it can often contribute enhancing neuronal damage. Thus, the inflammatory response in the CNS may have both neuroprotective and deleterious effects, depending on the circumstances $[113,114]$. The innate immune system is the first to be activated to trigger an immunologic response and it acts through sensing of pathogen-associated molecular patterns (PAMPs) derived from invading pathogens, and danger-associated molecular patterns (DAMPs) [115]. In the CNS, pattern-recognition receptors are primarily expressed by microglia, macrophages, and astrocytes. Microglia cells are often termed the "sentinel of brain parenchyma" because they are constantly in a state of alert to detect pathogen's invasion through the pattern-recognition receptors (PRR) that they express [116]. They can display two different types of receptors: Toll-like receptors (TLRs) that are membrane spanning receptors, and Nod-like receptors (NLRs), which are cytoplasmic sensors able to oligomerize and form a platform for the inflammasome $[115,117]$.

Inflammasomes are cytosolic multimolecular complexes that need to be activated to initiate and sustain the inflammatory response and they are formed by microglia and macrophages within the §CNS $[114,115]$. They are usually constituted by three main components: a cytosolic pattern-recognition receptor, the enzyme caspase 1 and an adaptor protein, apoptosis-associated speck-like protein containing a CARD (ASC), that facilitates the interaction between the former components. According to the variable amino-terminal domain displayed, there are several subfamilies within the NLR family. Whereas members of the NLRP subfamily carry an N-terminal pyrin domain (PYD) that interacts with the pyrin domain of ASC to bridge the complex to pro-caspase-1, the NLRs containing a caspase activation and recruitment domain (CARD) bind directly to pro-caspase 1 . The inflammasome assembly leads to caspase- 1 activation that converts the cytokine precursors pro-IL- $1 \beta$ and pro-IL-18 into mature and bioactive form IL-1 $\beta$ and IL-18, respectively, which are two pro-inflammatory cytokines involved in neuroimmunomodulation, neuroinflammation and neurodegeneration. These cytokines trigger signaling cascades that culminate in a type of inflammatory neuronal death termed pyroptosis $[114,115,117,118]$. There are two well-established pathways for NLRP3 inflammasome activation and an alternative NLPR3 inflammasome activation pathway was recently described that occurs exclusively in human monocytes $[115,118,119]$.

Strong evidence has emerged implying the involvement of inflammasomes in the initiation or progression of diseases with a high social and health impact, such as metabolic disorders and neurological diseases, including meningitis, stroke and Alzheimer's disease [114,115]. Furthermore, activation of the immune system has been consistently reported in BD $[120,121]$ and in the last few years, evidence has been emerged implying activation of the NLRP3 inflammasome in BD pathophysiology [17]. Altered levels of inflammatory cytokines were shown in the brain and periphery of patients with BD, suggesting that activation of the inflammatory system may play a role in the pathophysiology of BD [120]. Recent studies suggest that mitochondrial production of ROS may be linked to inflammatory activation. In fact, increased ROS production in result of inhibition of complex I of the mitochondrial respiratory chain led to increased levels of inflammatory factors such as IL-1, caspase 1, and NF-B and was recently linked to activation of an inflammatory redox sensor, the NLRP3. Post-mortem analysis of frontal cortex from BD patients showed lower levels of complex I and NDUFS7, a subunit of complex I, concomitantly with higher levels of mitochondrial NLRP3 and ASC and increased levels of caspase 1, IL-1 $\beta$, IL-6, TNF $\alpha$ and IL-10 [17], suggesting that brain immune-activation in patients with $\mathrm{BD}$ is associated with mitochondrial dysfunction and NLRP3-inflammasome activation. Because inflammasome activation is recognized as a regulatory function associated with the specific membranous ER-mitochondria microdomains [122] a link between interorganelle miscommunication and NLRP3 activation in BD can be anticipated. Recently, it was found that genetic deficiency in vitro of caspase-1 decreased depressive- and anxiety-like behaviors and prevented the exacerbation of depressive-like behaviors following chronic stress [123] . This linkage is also supported by the fact that the induction of an inflammatory response in other neuropsychiatric diseases requires inflammasome activation [115]. Finally, Haneklaus and colleagues demonstrated that both NLRP3 inflammasome formation and IL$1 \beta$ production are regulated by microRNAs that have been implicated in BD pathophysiology [124].

\section{Intercellular communication mediated by microRNAs}

MicroRNAs (miRNAs) are a class of endogenous, small, non-coding RNAs that post-transcriptionally regulate gene expression and are highly expressed in the brain, which have emerged as essential regulators of neuronal development, differentiation, and neuroplasticity [125] miRNAS are present in tissues and in circulating fluids, particularly in the blood and several reports highlight differences of composition in disease states [126]. A peripheral blood compartment that may be particularly relevant are the exosomes, cellular miRNAs-containing secretory vesicles able to attach recipient cells and release miRNAs potentially modulating their function [127]. Recent results clearly indicate that miRNAs are important mediators of stress responses and their deregulation has been implicated in a variety of stress-related neuropathological conditions $[128,129]$. Accordingly, UPR regulates the expression of many miRNAs that play an important role in the regulation of life and death decisions during ER stress [130]. There is 
accumulated evidence linking deregulation of numerous miRNAs with neuropsychiatric disorders, including BD. The problem of multiple susceptibility genes of small effect in BD has led to an increased interest in miRNAs. The mood stabilizer VPA used for treatment of BD has been shown to induce proteasomal degradation of Dicer, which causes a general down-regulation of miRNA expression, suggesting that VPA have some influence on BD psychopathology through the modification of miRNA biogenesis [131]. Evidence from postmortem cortical brain tissue from affected individuals, as well as from BD patient-derived neuronal cultures generated by reprogramming of human fibroblasts into iPSCs subsequently differentiated into neurons, demonstrate the deregulation of specific miRNAs in BD compared to control subjects [20]. Some of these miRNA, such as miR-34a, directly target the BD risk genes ANK3 and voltage-dependent L-type calcium channel subunit beta-3 (CACNB3) and modulate neuronal differentiation, expression of synaptic proteins and neuronal morphology [28]. Genome-wide analysis followed by target gene and pathway analysis of brain-expressed miRNAs support that miR-499, miR-708 and miR-1908 genes and their targets may be implicated in the development of BD [29]. MiR-499 regulates mitochondrial dynamics and apoptotic pathways involving the $\mathrm{Ca}^{2+}$-dependent protein phosphatase calcineurin [132]. and the risk gene for psychiatric disorders CACNB2.51 is a miR-499 target gene [29]. Recent pathway analysis also indicates a potential role of miR-499 in the regulation of the actin cytoskeleton [29]. that is crucial for neuronal cell migration and maturation, neurite outgrowth and maintenance of synaptic density and plasticity. The miRNA miR-708 is located in the first intron of ODZ4, a human homolog of the Drosophila pair-rule gene ten-m (odz), which has been reported as a genome-wide significant susceptibility gene for $\mathrm{BD}$. It was recently found that miR-708 regulates the expression of neuronatin, which is a membrane protein in the ER, and neuronatin-mediated regulation of intracellular $\mathrm{Ca}^{2+}$ levels has been implicated in cell migration and neural induction within embryonic stem cells [133]. MiR-1908 was showed to belong to a miRNA cluster that downregulates the MARK1 signaling pathway, thus altering cell proliferation and differentiation [134]. Kim and colleagues [135] identified and validated DLGAP4, GRIN1, STX1A, CLSTN1 and GRM4, which all function in neuronal glutamatergic synapses, as target genes of the recently identified BD-associated miRNA, miR-1908-5p, supporting the hypothesis that neuronal synapses could be a key converging pathway of some BD-associated protein-coding genes and miRNAs. A deregulation of miRNA blood expression and the differential expression of exosomal miRNAs were recently observed in BD patients [136,137], which may represent potential peripheral biomarkers to be complemented with other clinical and biological features for the improvement of diagnostic accuracy.

\section{Concluding remarks}

The former Director of the National Institute of Mental Health (USA), Tom Insel, said recently: "Without biology, there is no treatment for mental disorders". BD is a chronic mental illness that follows a relapsing/remitting course requiring lifetime treatment. However, few treatments are available and have limited efficacy. Lack of biological markers is another difficulty in clinical practice. A growing body of evidence suggests that $\mathrm{BD}$ pathogenesis is closely related with cellular plasticity defects, including in brain cells ability to resist or adapt to environmental stressors (cellular resilience). Results obtained in the last years using postmortem brain tissue from BD patients and also patient-derived cellular models support the hypothesis that disturbance of MAMs, which are crucial for determining cell fate under stress conditions, plays a major role in $\mathrm{BD}$ pathophysiology and that MAMs are relevant targets to develop new treatments and biomarkers for early diagnosis.

\section{Abbreviations}

ANK3: ankyrin-3; ASC: apoptosis-associated speck-like protein containing a CARD; ATF4: activating transcription factor 4; ATF6: activation of transcription factor 6; ATP: adenosine-5-triphosphate; BD: Bipolar disorder; CACNA1C : calcium voltage-gated channel subunit alpha $1 \mathrm{C}$; CACNB3: Calcium channel subunit beta-3; CARD: caspase activation and recruitment domain; CBZ: carbamazepine; CHOP: CAAT/enhancer binding protein homologous protein; CNS: central nervous system; CRMP2: collapsin response mediator protein-2; DAMPs: danger-associated molecular patterns; DISC1: Disrupted-In-Schizophrenia 1; eIF2 $\alpha$ : $\alpha$-subunit of eukaryotic translation-initiation factor $2 \alpha$; ER: endoplasmic reticulum; ERAD: ER-associated degradation; GRP78: glucose-regulated protein 78; GWAS: genome-wide association studies; HNE: 4-hydroxy-2-nonenal; iPSCs : induced pluripotent stem cells; IRE1 $\alpha$ : inositol-requiring enzyme $1 \alpha$; iRNAs: microRNAs; JNK: c-Jun NH2-terminal kinase; LTCC: L-type Ca2+ channel; MAMs: Mitochondria-Associated Membranes; miRNAs: MicroRNAs; mtDNA: mitochondrial DNA; nArgBP2: neural abelson-related gene-binding protein 2; NLRs: Nodlike receptors; NMDARs: N-methyl-D-aspartate receptors; PAMPs: pathogen-associated molecular patterns; PERK: protein kinase R-like endoplasmic reticulum kinase; PRR: pattern-recognition receptors; PYD: pyrin domain; ROS: reactive oxygen species; SAPAP3: SAP90/PS95-associated protein 3; Shank3: SH3 and multiple ankyrin repeat domains 3; S1P and S2P: Site 1 and Site 2 proteases; Sig-1R: Sigma-1 receptor; SNPs: single polymorphisms; TLRs: Toll-like receptors; UPR: unfolded protein response; UPRE: unfolded protein response element; UPS: ubiquitin proteasome pathway; VPA: valproic acid; XBP1: X-box binding protein 1

\section{Acknowledgments}

This work was supported by FEDER funds through the Operational Programme Competitiveness Factors - COMPETE 2020 and by national funds by FCT - Foundation for Science and Technology under the strategic project COMPETE: POCI-01-0145-FEDER-007440. Rosa Resende is recipient of a FCT fellowship.

\section{Author's contribution}

All authors contributed to the content, organization and writing of the manuscript.

\section{Competing interests}

The authors declare no conflict of interest. 


\section{References}

1. Merikangas KR, Jin R, He JP, Kessler RC, Lee S, Sampson, NA, Viana MC, Andrade LH, Hu C, Karam EG, Ladea M, Medina-Mora ME, Ono Y, Posada-Villa J, Sagar R, Wells JE, Zarkov Z. Prevalence and correlates of bipolar spectrum disorder in the world mental health survey initiative. Arch Gen Psychiatry 2011; 68:241-251. https://doi.org/10.1001/archgenpsychiatry.2011.12

2. Goodwin FK, Jamison KR. Manic-depressive Illness. Psychol Med 1991; 21:803-803.

3. DiLuca M, Olesen J. The cost of brain diseases: a burden or a challenge? Neuron 2014; 82:1205-1208. https://doi.org/10.1016/j.neuron.2014.05.044

4. Murray CJ, Lopez AD. Evidence-based health policy- lessons fro the Global Burden of Disease Study. Science 1996; 274:740-743. https://doi.org/10.1126/science.274.5288.740

5. Vancampfort D, Correll CU, Galling B, Probst M, De Hert M, Ward PB, Rosenbaum S, Gaughran F, Lally J, Stubbs B. Diabetes mellitus in people with schizophrenia, bipolar disorder and major depressive disorder: a systematic review and large scale meta-analysis. World Psychiatry 2016; 15:166-174. https://doi.org/10.1002/wps.20309

6. Kattimani S, Subramanian K, Sarkar S, Rajkumar RP, Balasubramanian S. History of lifetime suicide attempt in bipolar I disorder: its correlates and effect on illness course. Int J Psychiatry Clin Pract 2016; 21:118-124. https://doi.org/10.1080/13651501.2016.1250912

7. SayuriYamagata A, Brietzke E, Rosenblat JD, Kakar R, McIntyre RS. Medical comorbidity in bipolar disorder: The link with metabolic-inflammatory systems. J Affect Disord 2017; 211:99-106. https://doi.org/10.1016/j.jad.2016.12.059

8. Kim Y, Santos R, Gage FH, Marchetto MC. Molecular mechanisms of Bipolar disorder: progress made and future challenges. Front Cell Neurosci 2017; 11:30. https://doi.org/10.3389/fncel.2017.00030

9. Oud M, Mayo-Wilson E, Braidwood R, Schulte P, Jones SH, Morriss R, Kupka R, Cuijpers P, Kendall T. Psychological interventions for adults with bipolar disorder: systematic review and meta-analysis. Br J Psychiatry 2016; 208:213-222. https://doi.org/10.1192/bjp.bp.114.157123

10. Goodwin GM, Anderson I, Arango C, Bowden CL, Henry C, Mitchell PB, Nolen WA, Vieta E, Wittchen HU. ECNP consensus meeting. Bipolar depression. Nice, March 2007. Eur Neuropsychopharmacol 2008; 18:535-549. https://doi.org/10.1016/j.euroneuro.2008.03.003

11. McCormick U, Murray B, McNew B. Diagnosis and treatment of patients with bipolar disorder: a review for advanced practice nurses. J Am Assoc Nurse Pract 2015; 27:530-542. https://doi.org/10.1002/2327-6924.12275

12. Geddes JR, Miklowitz DJ. Treatment of bipolar disorder. Lancet 2013; 381:1672-1682. https://doi.org/10.1016/S0140-6736(13)60857-0

13. Walker AJ, Kim Y, Price JB, Kale RP, McGillivray JA, Berk M, Tye SJ. Stress, inflammation, and cellular vulnerability during early stages of affective disorders: biomarker strategies and opportunities for prevention and intervention. Front Psychiatry 2014; 5:34. https://doi.org/10.3389/fpsyt.2014.00034

14. Machado-Vieira R, Soeiro-De-Souza MG, Richards EM, Teixeira AL, Zarate CA Jr. Multiple levels of impaired neural plasticity and cellular resilience in bipolar disorder: developing treatments using an integrated translational approach. World J Biol Psychiatry 2014; 15:84-95. https://doi.org/10.3109/15622975.2013.830775

15. Pfaffenseller B, da Silva Magalhães PV, De Bastiani MA, Castro MA, Gallitano AL, Kapczinski F, Klamt F. Differential expression of transcriptional regulatory units in the prefrontal cortex of patients with bipolar disorder: potential role of early growth response gene 3. Transl Psychiatry 2016; 6:e805.

https://doi.org/10.1038/tp.2016.78

16. Viswanath B, Jose SP, Squassina A, Thirthalli J, Purushottam M, Mukherjee O, Vladimirov V, Patrinos GP, Del Zompo M, Jain S; Cellular models to study bipolar disorder: A systematic review. J Affect Disord 2015; 184:36-50. https://doi.org/10.1016/j.jad.2015.05.037

17. Kim S, Kim MK, Oh D, Lee SH, Kim B. Induced pluripotent stem cells as a novel tool in psychiatric research. Psychiatry Investig 2016; 13:8-17. https://doi.org/10.4306/pi.2016.13.1.8

18. Stern S, Santos R, Marchetto MC, Mendes AP, Rouleau GA, Biesmans S, Wang QW, Yao J, Charnay P, Bang AG, Alda M, Gage FH. Neurons derived from patients with bipolar disorder divide into intrinsically different sub-populations of neurons, predicting the patients' responsiveness to lithium. Mol Psychiatry 2017 (in press). https://doi.org/10.1038/mp.2016.260

19. Pfaffenseller, B., Wollenhaupt-Aguiar, B., Fries, G. R., Colpo, G. D., Burque, R. K., Bristot, G., Ferrari, P., Cereser, K. M., Rosa, A. R., Klamt, F. \& Kapczinski, F. Impaired endoplasmic reticulum stress response in bipolar disorder: cellular evidence of illness progression. Int J Neuropsychopharmacol 2014; 17(9), 1453-63. https://doi.org/10.1017/S1461145714000443

20. Sun E, Shi Y. MicroRNAs: Small molecules with big roles in neurodevelopment and diseases. Exp Neurol 2014; pii:S00144886(14)00257-X.

21. Bengesser SA, Fuchs R, Lackner N, Birner A, Reininghaus B, Meier-Allard N, Stracke A, Kapfhammer HP, Reininghaus EZ, Wallner-Liebmann S. Endoplasmic reticulum stress and Bipolar disorder - almost forgotten therapeutic drug targets in the Unfolded Protein Response pathway revisited. CNS Neurol Disord Drug Targets 2016; 15:403-413. https://doi.org/10.2174/1871527315666160321104613

22. Chen HM, DeLong CJ, Bame M, Rajapakse I, Herron TJ, McInnis MG and O'Shea KS. Transcripts involved in calcium signaling and telencephalic neuronal fate are altered in induced pluripotent stem cells from bipolar disorder patients. Transl Psychiatry 2014; 4:e375. https://doi.org/10.1038/tp.2014.12

23. Kim, H. K., Andreazza, A. C., Elmi, N., Chen, W. \& Young, L. T. Nod-like receptor pyrin containing 3 (NLRP3) in the post-mortem frontal cortex from patients with bipolar disorder: A potential mediator between mitochondria and immune-activation. J Psychiatr Res 2016; 72, 43-50. https://doi.org/10.1016/j.jpsychires.2015.10.015

24. Morris G, Walder K, McGee SL, Dean OM, Tye SJ, Maes M, Berk M. A model of the mitochondrial basis of bipolar disorder. Neurosci Biobehav Rev 2017; 74(Pt A):1-20.

25. Muneer A. The neurobiology of Bipolar disorder: an integrated approach. Chonnam Med J 2016; 52:18-37. https://doi.org/10.4068/cmj.2016.52.1.18

26. Data-Franco J, Singh A, Popovic D, Ashton M, Berk M, Vieta E, Figueira ML, Dean OM. Beyond the therapeutic shackles of the monoamines: New mechanisms in bipolar disorder biology. Prog Neuropsychopharmacol Biol Psychiatry 2017; 72:73-86. https://doi.org/10.1016/j.pnpbp.2016.09.004

27. Tobe BTD, Crain AM, Winquist AM, Calabrese B, Makihara H, Zhao WN, Lalonde J, Nakamura H, Konopaske G, Sidor M, Pernia CD, Yamashita N, Wada M, Inoue Y, Nakamura F, Sheridan SD, Logan RW, Brandel M, Wu D, Hunsberger J, Dorsett L, Duerr C, Basa RCB, McCarthy MJ, Udeshi N, Mertins P, Carr SA, Rouleau GA, Mastrangelo L, Li J, Gutierrez GJ, Brill LM, Venizelos N, Chen G, Nye JS, Manji H, Price JH, McClung CA, Akiskal HS, Alda M, Chuang DM, Coyle JT, Liu Y, Teng YD, Ohshima T, Mikoshiba K, Sidman RL, Halpain S, Haggarty SJ, Goshima Y, Snyder EY. Probing the lithium-response pathway in hiPSCs implicates the 
phosphoregulatory set-point for a cytoskeletal modulator in bipolar pathogenesis. Proc Natl Acad Sci USA 2017; 114:E4462-E4471. https://doi.org/10.1073/pnas.1700111114

28. Bavamian S, Mellios N, Lalonde J, Fass DM, Wang J, Sheridan SD, Madison JM, Zhou F, Rueckert EH, Barker D, Perlis RH, Sur M, Haggarty SJ; Dysregulation of miR-34a links neuronal development to genetic risk factors for bipolar disorder. Mol Psychiatry 2015; 20:573-84.

https://doi.org/10.1038/mp.2014.176

29. Forstner AJ, Hofmann A, Maaser A, Sumer S, Khudayberdiev S, Mühleisen TW, Leber M, Schulze TG, Strohmaier J, Degenhardt F, Treutlein J, Mattheisen M, Schumacher J, Breuer R, Meier S, Herms S, Hoffmann P, Lacour A, Witt SH, Reif A, Müller-Myhsok B, Lucae S, Maier W, Schwarz M, Vedder H, Kammerer-Ciernioch J, Pfennig A, Bauer M, Hautzinger M, Moebus S, Priebe L, Sivalingam S, Verhaert A, Schulz H, Czerski PM, Hauser J, Lissowska J, Szeszenia-Dabrowska N, Brennan P, McKay JD, Wright A, Mitchell PB, Fullerton JM, Schofield PR, Montgomery GW, Medland SE, Gordon SD, Martin NG, Krasnov V, Chuchalin A, Babadjanova G, Pantelejeva G, Abramova LI, Tiganov AS, Polonikov A, Khusnutdinova E, Alda M, Cruceanu C, Rouleau GA, Turecki G, Laprise C, Rivas F, Mayoral F, Kogevinas M, Grigoroiu-Serbanescu M, Propping P, Becker T, Rietschel M, Cichon S, Schratt G, Nöthen MM. Genome-wide analysis implicates microRNAs and their target genes in the development of bipolar disorder. Transl Psychiatry 2015; 5:e678. https://doi.org/10.1038/tp.2015.159

30. Area-Gomez E, Del Carmen Lara Castillo M, Tambini MD, Guardia-Laguarta C, de Groof AJ, Madra M, Ikenouchi J, Umeda M, Bird TD, Sturley SL, Schon E. Upregulated function of mitochondria-associated ER membranes in Alzheimer disease. EMBO J 2012; 31:4106-4123.

https://doi.org/10.1038/emboj.2012.202

31. Rowland AA, Voeltz GK. Endoplasmic reticulum-mitochondria contacts: function of the junction. Nat Rev Mol Cell Biol 2012; 13:607-625.

https://doi.org/10.1038/nrm3440

32. van Vliet AR, Verfaillie T, Agostinis P. New functions of mitochondria associated membranes in cellular signaling. Biochim Biophys Acta 2014; 1843:2253-2262. https://doi.org/10.1016/j.bbamcr.2014.03.009

33. Filadi, R., Theurey, P. \& Pizzo, P. The endoplasmic reticulum-mitochondria coupling in health and disease: Molecules, functions and significance. Cell Calcium 2017; 62, 1-15. https://doi.org/10.1016/j.ceca.2017.01.003

34. Hetz, C. \& Mollereau, B. Disturbance of endoplasmic reticulum proteostasis in neurodegenerative diseases. Nat Rev Neurosci 2014; 15(4), 233-49.

https://doi.org/10.1038/nrn3689

35. Joshi AU, Kornfeld OS, Mochly-Rosen D. The entangled ER-mitochondrial axis as a potential therapeutic strategy in neurodegeneration: a tangled duo unchained. Cell Calcium 2016; 60:218-234. https://doi.org/10.1016/j.ceca.2016.04.010

36. Hayashi T, Su TP. Sigma-1 receptor chaperones at the ER-mitochondrion interface regulate $\mathrm{Ca}(2+)$ signaling and cell survival. Cell 2007; 131:596-610. https://doi.org/10.1016/j.cell.2007.08.036

37. Hayashi T. Sigma-1 receptor: the novel intracellular target of neuropsychotherapeutic drugs. J Pharmacol Sci 2015; 12:2-5. https://doi.org/10.1016/j.jphs.2014.07.001

38. Hashimoto K. Activation of sigma-1 receptor chaperone in the treatment of neuropsychiatric diseases and its clinical implication. J Pharmacol Sci 2015; 127:6-9. https://doi.org/10.1016/j.jphs.2014.11.010

39. Mandelli L, Wang SM, Han C, Lee SJ, Patkar AA, Masand PS, Pae $\mathrm{CU}$, Serretti A. The impact of a single nucleotide polymorphism in SIGMAR1 on depressive symptoms in Major Depressive Disorder and Bipolar Disorder. Adv Ther 2017; 3:713-724.

https://doi.org/10.1007/s12325-017-0482-2

40. Ohi K, Hashimoto R, Yasuda Y, Fukumoto M, Yamamori H, Umeda-Yano S, Kamino K, Ikezawa K, Azechi M, Iwase M, Kazui $\mathrm{H}$, Kasai K, Takeda M. The SIGMAR1 gene is associated with a risk of schizophrenia and activation of the prefrontal cortex. Prog Neuropsychopharmacol Biol Psychiatry 2011; 35:1309-1315. https://doi.org/10.1016/j.pnpbp.2011.04.008

41. Ruscher K, Wieloch T. The involvement of the sigma-1 receptor in neurodegeneration and neurorestoration. J Pharmacol Sci 2015; 127:30-35 https://doi.org/10.1016/j.jphs.2014.11.011

42. WTCC. Genome-wide association study of 14,000 cases of seven common diseases and 3,000 shared controls. Nature 2007; 447:661678. https://doi.org/10.1038/nature05911

43. Ament SA, Szelinger S, Glusman G, Ashworth J, Hou L, Akula N, Shekhtman T, Badner JA, Brunkow ME, Mauldin DE, Stittrich AB, Rouleau K, Detera-Wadleigh SD, Nurnberger JI Jr, Edenberg HJ, Gershon ES, Schork N; Bipolar Genome Study, Price ND, Gelinas R, Hood L, Craig D, McMahon FJ, Kelsoe J, Roach JC. Rare variants in neuronal excitability genes influence risk for bipolar disorder. Proc Natl Acad Sci USA 2015; 112:3576-3581. https://doi.org/10.1073/pnas.1424958112

44. Harraz OF, Altier C. STIM1-mediated bidirectional regulation of $\mathrm{Ca}(2+)$ entry through voltage-gated calcium channels (VGCC) and calcium-release activated channels (CRAC). Front Cell Neurosci 2014; 8:43. https://doi.org/10.3389/fncel.2014.00043

45. Kabir ZD, Martínez-Rivera A, Rajadhyaksha AM. From gene to behavior: L-type calcium channel mechanisms underlying neuropsychiatric symptoms. Neurotherapeutics. (in press) 2017. https://doi.org/10.1007/s13311-017-0532-0

46. Kline CF, Cunha SR, Lowe JS, Hund TJ, Mohler PJ. Revisiting ankyrin-InsP 3 receptor interactions: ankyrin-B associates with the cytoplasmic N-terminus of the InsP3 receptor. J Cell Biochem 2008; 104:1244-1253. https://doi.org/10.1002/jcb.21704

47. Soeiro-de-Souza MG, Lafer B, Moreno RA, Nery FG, Chile T, Chaim K, da Costa Leite C, Machado-Vieira R, Otaduy MC, Vallada H. The CACNA1C risk allele rs 1006737 is associated with age-related prefrontal cortical thinning in bipolar I disorder. Transl Psychiatry 2017; 7:e1086.

https://doi.org/10.1038/tp.2017.57

48. Ota M, Hori H, Sato N, Yoshida F, Hattori K, Teraishi T, Kunugi $H$.Effects of ankyrin 3 gene risk variants on brain structures in patients with bipolar disorder and healthy subjects. Psychiatry Clin Neurosci 2016; 70:498-506. https://doi.org/10.1111/pcn.12431

49. Föcking M, Dicker P, Lopez LM, Hryniewiecka M, Wynne K, English JA, Cagney G, Cotter DR. Proteomic analysis of the postsynaptic density implicates synaptic function and energy pathways in bipolar disorder. Transl Psychiatry 2016; 6:e959. https://doi.org/10.1038/tp.2016.224

50. Cipriani A, Saunders K, Attenburrow MJ, Stefaniak J, Panchal P, Stockton S, Lane TA, Tunbridge EM, Geddes JR, Harrison PJ. A systematic review of calcium channel antagonists in bipolar disorder and some considerations for their future development. Mol Psychiatry 2016; 21:1324-1332. https://doi.org/10.1038/mp.2016.86

51. Pasca SP, Portmann T, Voineagu I, Yazawa M, Shcheglovitov A, Pasca AM, Cord B, Palmer TD, Chikahisa S, Nishino S, Bernstein JA, Hallmayer J, Geschwind DH, Dolmetsch RE. Using iPSC-derived neurons to uncover cellular phenotypes associated with Timothy syndrome. Nat Med 2011; 17:1657-1662. https://doi.org/10.1038/nm.2576 
52. Mosca TJ, Hong W, Dani VS, Favaloro V, Luo L. Trans-synaptic Teneurin signalling in neuromuscular synapse organization and target choice. Nature 2012; 484:237-241 https://doi.org/10.1038/nature10923

53. Friedman JR, Webster BM, Mastronarde DN, Verhey KJ, Voeltz GK. ER sliding dynamics and ER-mitochondrial contacts occur on acetylated microtubules. J Cell Biol 2010; 190:363-375. https://doi.org/10.1083/jcb.200911024

54. Marchisella F, Coffey ET, Hollos P. Microtubule and microtubule associated protein anomalies in psychiatric disease. Cytoskeleton (Hoboken) 2016; 73:596-611. https://doi.org/10.1002/cm.21300

55. Solís-Chagoyán H, Calixto E, Figueroa A, Monta-o LM, Berlanga C, Rodríguez-Verdugo MS, Romo F, Jiménez M, Gurrola CZ, Riquelme A, Benítez-King G. Microtubule organization and L-type voltage-activated calcium current in olfactory neuronal cells obtained from patients with schizophrenia and bipolar disorder. Schizophr Res 2013; 143:384-389. https://doi.org/10.1016/j.schres.2012.11.035

56. Zhao Z, Xu J, Chen J, Kim S, Reimers M, Bacanu SA, Yu H, Liu C, Sun J, Wang Q, Jia P, Xu F, Zhang Y, Kendler KS, Peng Z, Chen X. Transcriptome sequencing and genome-wide association analyses reveal lysosomal function and actin cytoskeleton remodeling in schizophrenia and bipolar disorder. Mol Psychiatry 2015; 20:563-572. https://doi.org/10.1038/mp.2014.82

57. Lee SE, Chang S. nArgBP2 as a hub molecule in the etiology of various neuropsychiatric disorders. BMB Rep 2016; 49:457-458. https://doi.org/10.5483/BMBRep.2016.49.9.138

58. Lindholm D, Korhonen L, Eriksson O, Kõks S. Recent Insights into the Role of Unfolded Protein Response in ER Stress in Health and Disease. Front Cell Dev Biol 2017; 5:48. https://doi.org/10.3389/fcell.2017.00048

59. Decuypere JP, Monaco G, Bultynck G, Missiaen L, De Smedt H, Parys JB. The IP(3) receptor-mitochondria connection in apoptosis and autophagy. Biochim Biophys Acta 2011; 1813:1003-1013. https://doi.org/10.1016/j.bbamcr.2010.11.023

60. Deegan S, Saveljeva S, Gorman AM, Samali A. 2013 Stress-induced self-cannibalism: on the regulation of autophagy by endoplasmic reticulum stress. Cell Mol Life Sci 2013; 70:2425-2441. https://doi.org/10.1007/s00018-012-1173-4

61. Kim I, Xu W, Reed JC. Cell death and endoplasmic reticulum stress: disease relevance and therapeutic opportunities. Nat Rev Drug Discov 2008; 7:1013-1030. https://doi.org/10.1038/nrd2755

62. Tsang KY, Chan D, Bateman JF, Cheah KSE. In vivo cellular adaptation to ER stress: survival strategies with double-edged consequences. J Cell Sci 2010; 123:2145-2154. https://doi.org/10.1242/jcs.068833

63.Ron D, Walter P. Signal integration in the endoplasmic reticulum unfolded protein response. Nat Rev Mol Cell Biol 2007; 8:519-529. https://doi.org/10.1038/nrm2199

64. Bertolotti A, Zhang Y, Hendershot LM, Harding HP, Ron D. Dynamic interaction of BiP and ER stress transducers in the unfolded-protein response. Nat Cell Biol 2000; 2:326-332. https://doi.org/10.1038/35014014

65. Cox JS, Shamu CE, Walter P. Transcriptional induction of genes encoding endoplasmic reticulum resident proteins requires a transmembrane protein kinase. Cell 1993; 73:1197-1206. https://doi.org/10.1016/0092-8674(93)90648-A

66. Harding HP, Zhang Y, Ron D. 1999 Protein translation and folding are coupled by an endoplasmic-reticulum-resident kinase. Nature 1999; 397:271-274. https://doi.org/10.1038/16729

67. Harding HP, Zhang Y, Zeng H, Novoa I, Lu PD, Calfon M, Sadri N, Yun C, Popko B, Paules R, Stojdl DF, Bell JC, Hettmann T,
Leiden JM, Ron D. An integrated stress response regulates amino acid metabolism and resistance to oxidative stress. Mol Cell 2003; 11:619-633. https://doi.org/10.1016/S1097-2765(03)00105-9

68. Cullinan SB, Diehl JA. PERK-dependent activation of Nrf2 contributes to redox homeostasis and cell survival following endoplasmic reticulum stress. J Biol Chem 2004; 279:20108-20117. https://doi.org/10.1074/jbc.M314219200

69. Haze K, Yoshida H, Yanagi H, Yura T, Mori K. Mammalian transcription factor ATF6 is synthesized as a transmembrane protein and activated by proteolysis in response to endoplasmic reticulum stress. Mol Biol Cell 1999; 10:3787-3799. https://doi.org/10.1091/mbc.10.11.3787

70. Lai E, Teodoro T, Volchuk. Endoplasmic reticulum stress: signaling the unfolded protein response. Physiology (Bethesda) 2007; 22:193-201. https://doi.org/10.1152/physiol.00050.2006

71. Jadhav S, Russo S, Cottier S, Schneiter R, Cowart A, Greenberg ML. Valproate induces the unfolded protein response by increasing ceramide levels. J Biol Chem 2016; 291:22253-22261. https://doi.org/10.1074/jbc.M116.752634

72. Kakiuchi C, Iwamoto K, Ishiwata M, Bundo M, Kasahara T, Kusumi I, Tsujita T, Okazaki Y, Nanko S, Kunugi H, Sasaki T, Kato T. Impaired feedback regulation of XBP1 as a genetic risk factor for bipolar disorder. Nat Genet 2003; 35:171-175. https://doi.org/10.1038/ng1235

73. Jacobsen NJ, Lyons I, Hoogendoorn B, Burge S, Kwok PY, O'Donovan MC, Craddock N, Owen MJ. ATP2A2 mutations in Darier's disease and their relationship to neuropsychiatric phenotypes. Hum Mol Genet 1999; 8:1631-1636. https://doi.org/10.1093/hmg/8.9.1631

74. Machado-Vieira R, Pivovarova NB, Stanika RI, Yuan P, Wang Y, Zhou R, Zarate CA Jr, Drevets WC, Brantner CA, Baum A, Laje G, McMahon FJ, Chen G, Du J, Manji HK, Andrews SB. The Bcl-2 gene polymorphism rs956572AA increases inositol 1,4,5-trisphosphate receptor-mediated endoplasmic reticulum calcium release in subjects with bipolar disorder. Biol Psychiatry 2011; 69:344-352. https://doi.org/10.1016/j.biopsych.2010.10.019

75. Malavasi EL, Ogawa F, Porteous DJ, Millar JK. 2012 DISC1 variants $37 \mathrm{~W}$ and $607 \mathrm{~F}$ disrupt its nuclear targeting and regulatory role in ATF4-mediated transcription. Hum Mol Genet 2012; 21:2779-2792. https://doi.org/10.1093/hmg/dds106

76. Hroudova, J. \& Fisar, Z. Connectivity between mitochondrial functions and psychiatric disorders. Psychiatry Clin Neurosci 2011; 65(2), 130-41. https://doi.org/10.1111/j.1440-1819.2010.02178.x

77. Scaini, G., Rezin, G. T., Carvalho, A. F., Streck, E. L., Berk, M. \& Quevedo, J. Mitochondrial dysfunction in bipolar disorder: Evidence, pathophysiology and translational implications. Neurosci Biobehav Rev 2016; 68, 694-713. https://doi.org/10.1016/j.neubiorev.2016.06.040

78. Li, Z., Okamoto, K., Hayashi, Y. \& Sheng, M. The importance of dendritic mitochondria in the morphogenesis and plasticity of spines and synapses. Cell 2004; 119(6), 873-87. https://doi.org/10.1016/j.cell.2004.11.003

79. Kato, T. \& Kato, N. Mitochondrial dysfunction in bipolar disorder. Bipolar Disord 2000; 2(3 Pt 1), 180-90. https://doi.org/10.1034/j.1399-5618.2000.020305.x

80. Cikankova, T., Sigitova, E., Zverova, M., Fisar, Z., Raboch, J. \& Hroudova, J. Mitochondrial dysfunctions in bipolar disorder: effect of the disease and pharmacotherapy. CNS Neurol Disord Drug Targets. 2016.

81. Clay, H. B., Sillivan, S. \& Konradi, C. Mitochondrial dysfunction and pathology in bipolar disorder and schizophrenia. Int J Dev Neurosci 2011; 29(3), 311-24. https://doi.org/10.1016/j.ijdevneu.2010.08.007 
82. Brady, R. O., Jr., Cooper, A., Jensen, J. E., Tandon, N., Cohen, B., Renshaw, P., Keshavan, M. \& Ongur, D. A longitudinal pilot proton MRS investigation of the manic and euthymic states of bipolar disorder. Transl Psychiatry 2012; 2, e160. https://doi.org/10.1038/tp.2012.84

83. Norkett, R., Modi, S., Birsa, N., Atkin, T. A., Ivankovic, D., Pathania, M., Trossbach, S. V., Korth, C., Hirst, W. D. \& Kittler, J. T. DISC1-dependent Regulation of Mitochondrial Dynamics Controls the Morphogenesis of Complex Neuronal Dendrites. J Biol Chem 2016; 291(2), 613-29. https://doi.org/10.1074/jbc.M115.699447

84. Maeda, K., Nwulia, E., Chang, J., Balkissoon, R., Ishizuka, K., Chen, H., Zandi, P., McInnis, M. G. \& Sawa, A. Differential expression of disrupted-in-schizophrenia (DISC1) in bipolar disorder. Biol Psychiatry 2006; 60(9), 929-35. https://doi.org/10.1016/j.biopsych.2006.03.032

85. Scola, G., Kim, H. K., Young, L. T. \& Andreazza, A. C. A fresh look at complex I in microarray data: clues to understanding disease-specific mitochondrial alterations in bipolar disorder. Biol Psychiatry 2013; 73(2), e4-5. https://doi.org/10.1016/j.biopsych.2012.06.028

86. Munkholm, K., Peijs, L., Vinberg, M. \& Kessing, L. V. A composite peripheral blood gene expression measure as a potential diagnostic biomarker in bipolar disorder. Transl Psychiatry 2015; 5, e614. https://doi.org/10.1038/tp.2015.110

87. Yoshimi, N., Futamura, T., Kakumoto, K., Salehi, A. M., Sellgren, C. M., Holmen-Larsson, J., Jakobsson, J., Palsson, E., Landen, M. \& Hashimoto, K. Blood metabolomics analysis identifies abnormalities in the citric acid cycle, urea cycle, and amino acid metabolism in bipolar disorder. BBA Clin 2016; 5, 151-8. https://doi.org/10.1016/j.bbacli.2016.03.008

88. Davis, A. K., DelBello, M. P., Eliassen, J., Welge, J., Blom, T. J., Fleck, D. E., Weber, W. A., Jarvis, K. B., Rummelhoff, E., Strakowski, S. M. \& Adler, C. M. Neurofunctional effects of quetiapine in patients with bipolar mania. Bipolar Disord 2015; 17(4), 444-9. https://doi.org/10.1111/bdi.12274

89. Halliwell, B. Biochemistry of oxidative stress. Biochem Soc Trans 2007; 35(Pt 5), 1147-50. https://doi.org/10.1042/BST0351147

90. Poprac P, Jomova K, Simunkova M, Kollar V, Rhodes CJ, Valko M. Targeting free radicals in oxidative stress-related human diseases. Trends Pharmacol Sci 2017; pii: S0165-6147(17)30097-4.

91. Roy J, Galano JM, Durand T, Le Guennec JY, Lee JC. Physiological role of reactive oxygen species as promoters of natural defenses. FASEB J 2017; pii: fj.201700170R.

92. Schieber M, Chandel NS. ROS function in redox signaling and oxidative stress. Curr Biol 2014; 24:R453-62. https://doi.org/10.1016/j.cub.2014.03.034

93. Andreazza AC, Kauer-Sant'Anna M, Frey BN, Bond DJ, Kapczinski F, Young LT, Yatham LN. Oxidative stress markers in bipolar disorder: a meta-analysis. J. Affect. Disord 2008; 111:135-144. https://doi.org/10.1016/j.jad.2008.04.013

94. Brown NC, Andreazza AC, Young LT. An updated meta-analysis of oxidative stress markers in bipolar disorder. Psychiatry Res 2014; 218:61-68. https://doi.org/10.1016/j.psychres.2014.04.005

95. Andreazza AC, Wang JF, Salmasi F, Shao L, Young LT. Specific subcellular changes in oxidative stress in prefrontal cortex from patients with bipolar disorder. J Neurochem 2013; 127:552-561. https://doi.org/10.1111/jnc.12316

96. Romano A, Serviddio G, Calcagnini S, Villani R, Giudetti AM, Cassano T, Gaetani S. Linking lipid peroxidation and neuropsychiatric disorders: focus on 4-hydroxy-2-nonenal. Free Radic Biol Med 2017; pii: S0891-5849(16)31147-9.
97. Che Y, Wang JF, Shao L, Young T. Oxidative damage to RNA but not DNA in the hippocampus of patients with major mental illness. J Psychiatry Neurosci 2010; 35:296-302. https://doi.org/10.1503/jpn.090083

98. Soeiro-de-Souza MG, Andreazza AC, Carvalho AF, Machado-Vieira R, Young LT, Moreno RA. Number of manic episodes is associated with elevated DNA oxidation in bipolar I disorder. Int J Neuropsychopharmacol 2013; 16:1505-1512. https://doi.org/10.1017/S1461145713000047

99. Lagopoulos J, Hermens DF, Tobias-Webb J, Duffy S, Naismith SL, White D, Scott E, Hickie IB. In vivo glutathione levels in young persons with bipolar disorder: a magnetic resonance spectroscopy study. J Psychiatr Res 2013; 47:412-417. https://doi.org/10.1016/j.jpsychires.2012.12.006

100. Rosa AR, Singh N, Whitaker E, de Brito M, Lewis AM, Vieta E, Churchill GC, Geddes JR, Goodwin GM. Altered plasma glutathione levels in bipolar disorder indicates higher oxidative stress; a possible risk factor for illness onset despite normal brain-derived neurotrophic factor (BDNF) levels. Psychol Med 2014; 44:2409-2418. https://doi.org/10.1017/S0033291714000014

101. Hatch J, Andreazza A, Olowoyeye O, Rezin GT, Moody A, Goldstein BI. Cardiovascular and psychiatric characteristics associated with oxidative stress markers among adolescents with bipolar disorder. J Psychosom Res 2015; 79:222-227. https://doi.org/10.1016/j.jpsychores.2015.04.005

102. Andreazza AC, Gildengers A, Rajji TK, Zuzarte PM, Mulsant BH Young LT. Oxidative stress in older patients with bipolar disorder. Am J Geriatr Psychiatry 2015; 23:314-319. https://doi.org/10.1016/j.jagp.2014.05.008

103. Scola G, McNamara RK, Croarkin PE, Leffler JM, Cullen KR, Geske JR, Biernacka JM, Frye MA, DelBello MP, Andreazza AC. Lipid peroxidation biomarkers in adolescents with or at high-risk for bipolar disorder. J Affect Disord; 192:176-183.https://doi. org/10.1016/j.jad.2015.12.020

104. Andreazza AC, Cassini C, Rosa AR, Leite MC, de Almeida LMV, Nardin PC, Cunha AB, Ceresér KM, Santin A, Gottfried C, Salvador M, Kapczinski F, Gonçalves CA. Serum S100B and antioxidant enzymes in bipolar patients. J Psychiatr Res 2007; 41:523-529. https://doi.org/10.1016/j.jpsychires.2006.07.013

105. Cui J, Shao L, Young LT, Wang JF. Role of glutathione in neuroprotective effects of mood stabilizing drugs lithium and valproate. Neuroscience 2007; 144(4):1447-53. https://doi.org/10.1016/j.neuroscience.2006.11.010

106. Andreazza AC, Pharm D, Kauer-Sant'Anna M, Frey BN, Stertz L, Zanotto C, Ribeiro L, Giasson K, Valvassori SS, Réus GZ, Salvador M, Quevedo J, Gonçalves CA, Kapczinski F. Effects of mood stabilizers on DNA damage in an animal model of mania. J Psychiatry Neurosci 2008; 33:516-552.

107. Bakare A, Shao L, Cui J, Young LT. Wang J-F. Mood stabilizing drugs lamotrigine and olanzapine increase expression and activity of glutathione s-transferase in primary cultured rat cerebral cortical cells. Neurosci Lett 2009; 455:70-73. https://doi.org/10.1016/j.neulet.2009.03.022

108. Jornada LK, Valvassori SS, Steckert AV, Moretti M, Mina F, Ferreira C, Arent CO, Dal-Pizzol F, Quevedo J. Lithium and valproate modulate antioxidant enzymes and prevent ouabain-induced oxidative damage in an animal model of mania. J Psychiatr Res 2011; 45:162-168 https://doi.org/10.1016/j.jpsychires.2010.05.011

109. Banerjee U, Dasgupta A, Rout JK, Singh OP. Effects of lithium therapy on $\mathrm{Na}+\mathrm{K}+-\mathrm{ATPase}$ activity and lipid peroxidation in bipolar disorder. Prog. Neuropsychopharmacol Biol Psychiatry 2012; 37:56-61.

https://doi.org/10.1016/j.pnpbp.2011.12.006 
110. de Sousa RT, Zarate CA, Zanetti MV, Costa AC, Talib LL, Gattaz WF, Machado-Vieira R. Oxidative stress in early stage bipolar disorder and the association with response to lithium. J Psychiatr Res 2014; 50:36-41. https://doi.org/10.1016/j.jpsychires.2013.11.011

111. Polajnar, M. \& Zerovnik, E. Impaired autophagy: a link between neurodegenerative and neuropsychiatric diseases. J Cell Mol Med 2014: 18(9), 1705-11.

https://doi.org/10.1111/jcmm.12349

112. Calamini, B. \& Morimoto, R. I. Protein homeostasis as a therapeutic target for diseases of protein conformation. Curr Top Med Chem 201; 12(22), 2623-40.

113. Amor, S., Puentes, F., Baker, D. \& van der Valk, P. Inflammation in neurodegenerative diseases. Immunology 2010; 129(2), 154-69. https://doi.org/10.1111/j.1365-2567.2009.03225.x

114. Guo, H., Callaway, J. B. \& Ting, J. P. Inflammasomes: mechanism of action, role in disease, and therapeutics. Nat Med 2015; 21(7), 677-87. https://doi.org/10.1038/nm.3893

115. Walsh, J. G., Muruve, D. A. \& Power, C. Inflammasomes in the CNS. Nat Rev Neurosci 2014; 15(2), 84-97. https://doi.org/10.1038/nrn3638

116. Ginhoux, F., Lim, S., Hoeffel, G., Low, D. \& Huber, T. Origin and differentiation of microglia. Front Cell Neurosci 2013; 7, 45. https://doi.org/10.3389/fncel.2013.00045

117. Hanamsagar, R., Hanke, M. L. \& Kielian, T. Toll-like receptor (TLR) and inflammasome actions in the central nervous system. Trends Immunol 2012; 33(7), 333-42. https://doi.org/10.1016/j.it.2012.03.001

118. He, Y., Hara, H. \& Nunez, G. Mechanism and Regulation of NLRP3 Inflammasome Activation. Trends Biochem Sci 2016; 41(12), 1012-1021. https://doi.org/10.1016/j.tibs.2016.09.002

119. Gaidt, M. M., Ebert, T. S., Chauhan, D., Schmidt, T., SchmidBurgk, J. L., Rapino, F., Robertson, A. A., Cooper, M. A., Graf, T. \& Hornung, V. Human Monocytes Engage an Alternative Inflammasome Pathway. Immunity 2016; 44(4), 833-46. https://doi.org/10.1016/j.immuni.2016.01.012

120. Munkholm, K., Brauner, J. V., Kessing, L. V. \& Vinberg, M. Cytokines in bipolar disorder vs. healthy control subjects: a systematic review and meta-analysis. J Psychiatr Res 2013; 47(9), 1119-33. https://doi.org/10.1016/j.jpsychires.2013.05.018

121. Watkins, C. C., Sawa, A. \& Pomper, M. G. Glia and immune cell signaling in bipolar disorder: insights from neuropharmacology and molecular imaging to clinical application. Transl Psychiatry 2014; 4, e350.

https://doi.org/10.1038/tp.2013.119

122. Raturi, A. \& Simmen, T. Where the endoplasmic reticulum and the mitochondrion tie the knot: the mitochondria-associated membrane (MAM). Biochim Biophys Acta 2013; 1833(1), 213-24. https://doi.org/10.1016/j.bbamcr.2012.04.013

123. Wong, M. L., Inserra, A., Lewis, M. D., Mastronardi, C. A., Leong, L., Choo, J., Kentish, S., Xie, P., Morrison, M., Wesselingh, S. L., Rogers, G. B. \& Licinio, J. Inflammasome signaling affects anxiety- and depressive-like behavior and gut microbiome composition. Mol Psychiatry 2016; 21(6), 797-805.

https://doi.org/10.1038/mp.2016.46

124. Haneklaus, M., Gerlic, M., Kurowska-Stolarska, M., Rainey, A. A., Pich, D., McInnes, I. B., Hammerschmidt, W., O'Neill, L. A. \& Masters, S. L. Cutting edge: miR-223 and EBV miR-BART15 regulate the NLRP3 inflammasome and IL-1beta production. J Immunol 2012; 189(8), 3795-9.

https://doi.org/10.4049/jimmunol.1200312
125. Lagos-Quintana M, Rauhut R, Lendeckel W, Tuschl T. Identification of novel genes coding for small expressed RNAs. Science 2001; 294:853-858.

https://doi.org/10.1126/science.1064921

126. Jin XF, Wu N, Wang L, Li J.Circulating microRNAs: a novel class of potential biomarkers for diagnosing and prognosing central nervous system diseases. Cell Mol Neurobiol 2013; 33(5):601-13. https://doi.org/10.1007/s10571-013-9940-9

127. Valadi H, Ekström K, Bossios A, Sjöstrand M, Lee JJ, Lötvall JO () Exosome-mediated transfer of mRNAs and microRNAs is a novel mechanism of genetic exchange between cells. Nat Cell Biol 2007; 9:654-659.

https://doi.org/10.1038/ncb1596

128. Emde A, Hornstein E. miRNAs at the interface of cellular stress and disease. EMBO J 2014; 33(13):1428-37. https://doi.org/10.15252/embj.201488142

129. Hollins SL, Cairns MJ. MicroRNA: Small RNA mediators of the brains genomic response to environmental stress. Prog Neurobiol 2016; 143:61-81. https://doi.org/10.1016/j.pneurobio.2016.06.005

130. Gupta A, Hossain MM, Read DE, Hetz C, Samali A, Gupta S. PERK regulated miR-424(322)-503 cluster fine-tunes activation of IRE1 and ATF6 during Unfolded Protein Response. Sci Rep 2015; 5:18304. https://doi.org/10.1038/srep18304

131. Zhang Z, Convertini P, Shen M, Xu X, Lemoine F, de la Grange P, Andres DA, Stamm S. Valproic acid causes proteasomal degradation of DICER and influences miRNA expression. PLoS One 2013; 8(12):e82895. https://doi.org/10.1371/journal.pone.0082895

132. Wang JX, Jiao JQ, Li Q, Long B, Wang K, Liu JP, Li YR, Li PF. miR-499 regulates mitochondrial dynamics by targeting calcineurin and dynamin-related protein-1. Nat Med 2011; 17(1):71-8. https://doi.org/10.1038/nm.2282

133. Ryu S, McDonnell K, Choi H, Gao D, Hahn M, Joshi N, Park SM, Catena R, Do Y, Brazin J, Vahdat LT, Silver RB, Mittal V. Suppression of miRNA-708 by polycomb group promotes metastases by calcium-induced cell migration. Cancer Cell 2013; 23(1):63-76. https://doi.org/10.1016/j.ccr.2012.11.019

134. Ye SB, Li ZL, Luo DH, Huang BJ, Chen YS, Zhang XS, Cui J, Zeng YX, Li J. Tumor-derived exosomes promote tumor progression and $\mathrm{T}$-cell dysfunction through the regulation of enriched exosomal microRNAs in human nasopharyngeal carcinoma. Oncotarget 2014; 5(14):5439-52.

https://doi.org/10.18632/oncotarget.2118

135. Kim, Y., Zhang, Y., Pang, K., Kang, H., Park, H., Lee, Y., Lee, B., Lee, H. J., Kim, W. K., Geum, D. \& Han, K. Bipolar Disorder Associated microRNA, miR-1908-5p, Regulates the Expression of Genes Functioning in Neuronal Glutamatergic Synapses. Exp Neurobiol 2016; 25(6), 296-306. https://doi.org/10.5607/en.2016.25.6.296

136. Banigan MG, Kao PF, Kozubek JA, Winslow AR, Medina J, Costa J, Schmitt A, Schneider A, Cabral H, Cagsal-Getkin O, Vanderburg CR, Delalle I. Differential expression of exosomal microRNAs in prefrontal cortices of schizophrenia and bipolar disorder patients. PLoS One 2013; 8:e48814. https://doi.org/10.1371/journal.pone.0048814

137. Maffioletti E, Cattaneo A, Rosso G, Maina G, Maj C, Gennarelli M, Tardito D, Bocchio-Chiavetto L. Peripheral whole blood microRNA alterations in major depression and bipolar disorder. J Affect Disord 2016; 200:250-258.

https://doi.org/10.1016/j.jad.2016.04.021 